\title{
THYROID NODULES: A PUZZLE IN GYNAECOLOGICAL ENDOCRINOLOGY
}

\author{
Cristina VASILIU1,2, Simona E. ALBU ${ }^{1,2}$, Mara CARSOTE ${ }^{3,4} \bowtie$, Ana VALEA ${ }^{5,6}$, Adina \\ GHEMIGIAN $^{3,4}$, Ancuta-Augustina GHEORGHISAN-GALATEANU ${ }^{3,7}$
}

${ }^{1}$ „Carol Davila“ University of Medicine and Pharmacy, Department of Gynaecology, Bucharest, Romania

${ }^{2}$ University Emergency Hospital, Bucharest, Romania

${ }^{3}$ Carol Davila University of Medicine and Pharmacy, Department of Endocrinology, Bucharest, Romania

${ }^{4}$ „Constantin Ion Parhon“ National Institute of Endocrinology, Bucharest, Romania

5 „Iuliu Hatieganu“ University of Medicine and Pharmacy, Department of Endocrinology, Cluj-Napoca, Romania

${ }^{6}$ Clinical County Hospital, Department of Endocrinology, Cluj-Napoca, Romania

7 "Carol Davila“ University of Medicine and Pharmacy, Department of Molecular Biology, Bucharest, Romania

\section{Abstract}

Introduction. We present different particular aspects of the thyroid ultrasound in patients who were first referred to an endocrinologist after a gynaecological check-up.

Case series presentation. A 73-year-old woman was admitted for a routine gynaecological and general examination, after a thyroid nodule was incidentally detected. Ultrasonography showed a macronodule of $3.1 \mathrm{~cm}$, that was treated by surgery. A 53-year-old woman presented for hot flashes in association with high blood pressure episodes. Hyperthyroidism was not confirmed, but a conglomerate of thyroid nodules of $2.2 \mathrm{~cm}$ was detected. The fine needle aspiration excluded a malignancy. A 66-year old woman, presenting for bone assessment, was incidentally detected with a large multinodular goitre. The left lobe has multiple nodules including TIRADS4 conglomerate. A 43-year-old woman, with bilateral mammary cysts, normal TSH,

\section{Résumé}

Nodules thyroïdiens: un casse-tête dans l'endocrinologie gynécologique

Introduction. Nous présentons différents aspects de l'échographie thyroïdienne qui ont été référés à un endocrinologue après un examen gynécologique.

Série de cas. Une femme de 73 ans a été admise pour un examen gynécologique de routine et un examen général a accidentellement détecté un nodule thyroïdien. L'échographie a montré un macronodule de $3,1 \mathrm{~cm}$ avec une approche chirurgicale. Une femme de 53 ans a accusé des bouffées de chaleur, associées à des épisodes d'hypertension. L'hyperthyroïdie n'est pas confirmée mais un conglomérat de nodules de 2,2 $\mathrm{cm}$ a été trouvé. La ponction à l'aiguille fine exclut une tumeur maligne. Une femme de 66 ans se présentant pour une évaluation osseuse est détectée accidentellement avec un goitre multinodulaire de grande 
increased prolactin, presented at thyroid ultrasound a left lobe of $5.4 \mathrm{~cm}$, with a conglomerate of $3.3 \mathrm{~cm}$. The fine needle aspiration showed Hürthle cells and the patient was referred to surgery, which confirmed the diagnosis of follicular adenoma. A 41-year-old female, with a history of subtotal hysterectomy for uterine fibroma, presented for intermittent palpitations. TSH value was normal, but ultrasonography showed a mildly increased right lobe of $4.3 \mathrm{~cm}$, with multiple bilateral micronodular masses.

Conclusions. The thyroid ultrasound represents a very practical diagnostic method in daily gynaecologi$\mathrm{cal}$ endocrinology. The detection of a nodule may be related to routine menopausal evaluation, may be associated with clinical examination for bone menopausal status or may be associated to thyroid function assessment if hot flushes mimic hyperthyroidism.

Keywords: thyroid, ultrasound, nodule.

\section{INTRODUCTION}

Thyroid ultrasound is the best tool to assess thyroid anatomy in normal and pathological conditions $^{1-3}$. Despite the fact that it depends on the physician who performs the procedure, ultrasound represents an accessible method, useful for both pre- and post-menopausal women ${ }^{1-3}$.

\section{Case series presentation}

We present different particular aspects of the thyroid ultrasound in patients who were first referred to an endocrinologist after a gynaecological check-up. The ultrasound and endocrine parameters are provided based on an interdisciplinary perspective, both gynaecological and endocrine.

\section{Case 1}

A 73-year-old woman was admitted for a routine gynaecological control. No specific pathology was identified, but she accused non-specific constrictive cervical pain, so an endocrine check-up was considered necessary. The medical history includes type 2 diabetes mellitus, high blood pressure, currently controlled with specific oral medication. She comes from a non-endemic zone and the family medical history is irrelevant. The clinical examination of the thyroid detected gland enlargement, especially on the right site, with mobility taille. Le lobe gauche a plusieurs nodules inclus dans le conglomérat TIRADS4. Une femme de 43 ans avec des kystes mammaires bilatéraux a une TSH normale, une prolactine accrue et une échographie thyroïdienne avec un lobe gauche de $5,4 \mathrm{~cm}$ avec un conglomérat de $3,3 \mathrm{~cm}$. Une aspiration à l'aiguille fine a montré des cellules de Hürthle et le patient a été référé pour une intervention chirurgicale confirmant un adénome folliculaire. Une femme de 41 ans a subi il y a 7 ans une hystérectomie subtotale de fibrome utérin et associe actuellement des palpitations intermittentes. La TSH était normale alors que les ultrasons montraient une augmentation modérée du lobe droit de 4,3 $\mathrm{cm}$ avec de multiples masses micronodulaires bilatérales.

Conclusions. L'utilisation de l'échographie thyroïdienne représente une méthode extrêmement pratique dans l'endocrinologie gynécologique quotidienne. La détection d'un nodule peut être liée à une évaluation de routine de la ménopause, peut être associée à un examen clinique du statut de ménopause osseuse ou peut être associée à une évaluation de la fonction thyroïdienne si des bouffées de chaleur imitent l'hyperthyroïdie.

Mots-clés: thyroïde, échographie, nodule.

during deglutition and elastic consistence. The thyroid profile based on blood tests was within normal limits. However, at thyroid ultrasound the diameters of the right lobe were increased at $1.8 \times 2.5 \times 4.3 \mathrm{~cm}$, the left lobe being normal, $1.1 \times 1.3 \times 3.4 \mathrm{~cm}$. Both lobes had hypoechoic structure and the right lobe presented a

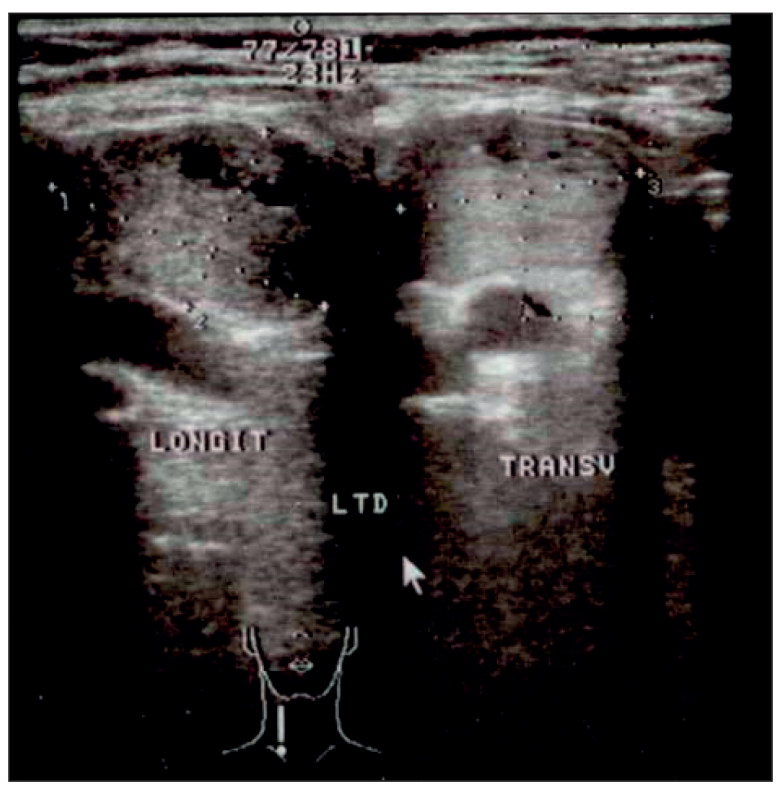

Fig. 1. Thyroid ultrasound in a 73-year-old woman showing a macronodule of the right lobe on longitudinal and transversal section. 


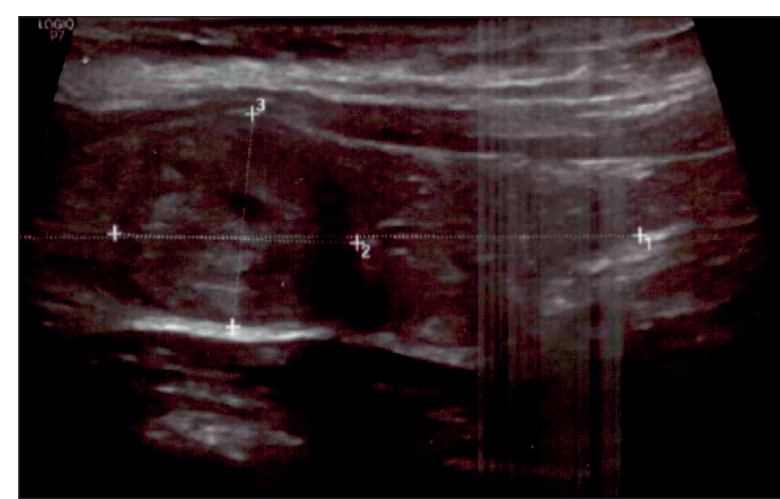

Fig. 2. Ultrasound - longitudinal section of the right lobe in a 53-year-old female with episodes of hot flushes and high blood pressure. Hypoechoic pattern and a tendency to nodularity are associated to inhomogeneous pattern.

macronodule of $3.1 \times 1.3 \times 2.47 \mathrm{~cm}$, well-shaped, with hypoechoic structure, a mild increase of peripheral vascularization (Fig. 1).

Due to the dimensions of the nodule, which are most probably the cause of constrictive complaints, total thyroidectomy was recommended. The anaesthesia risk related to the thyroid surgery was evaluated and the patient was found suitable for procedure. However, the patient refused the thyroid removal and she continued to be followed as an outpatient. The thyroid ultrasound estimated a low proliferative risk, so a low rate of growth is expected in this patient.

\section{Case 2}

A 53-year-old female accused hot flashes in association with high blood pressure episodes (4 episodes in the last 2 years, with a maximum value of systolic blood pressure of $230 \mathrm{mmHg}$ ). The personal and family histories were negative. The cardiologic evaluation recommended initiation of anti-hypertensive medication, with control of the arterial hypertension, but also a gynaecological and endocrine check-up was considered necessary. The patient did not experience similar symptoms after secondary surgical amenorrhea, when they were related to menopause (11 years ago, current FSH is $97 \mathrm{mUI} / \mathrm{mL}$ ), so she was referred for a thyroid stimulating hormone (TSH) evaluation, which excluded hyperthyroidism. Also, the evaluation of plasma and 24-hours urinary metanephrines and normetanephrines excluded a pheochromocytoma. Thyroid ultrasound showed both lobes with normal dimensions, of $1.6 \times 2 \times 4 \mathrm{~cm}$ on the right and of $1.4 \times 1.6 \times 2.4 \mathrm{~cm}$ on the left, with hypoechogenic, inhomogeneous pattern, and a tendency to nodularity (Fig. 2).

Multiple small nodules were identified at the isthmus junction, with the left lobe of $0.7 \times 0.3 \times 0.6$ $\mathrm{cm}$, and on the left lobe $2-3$ nodules of less than 0.5

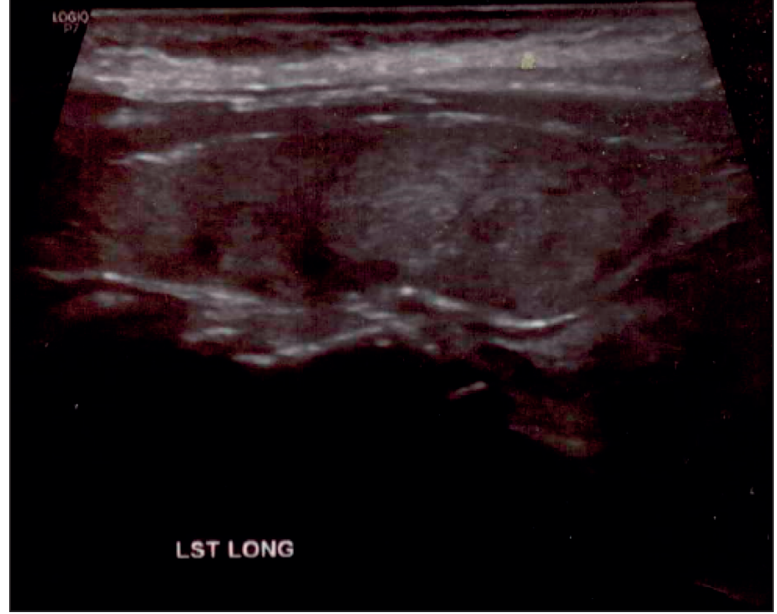

Fig. 3. Thyroid ultrasound shows a nodular conglomerate on the left lobe of $2.2 \times 1.3 \times 1.3 \mathrm{~cm}$.

$\mathrm{cm}$, another of $0.7 \times 0.4 \mathrm{~cm}$, and also a conglomerate of nodules of $2.2 \times 1.3 \times 1.3 \mathrm{~cm}$, with no local lymph nodes enlargement (Fig. 3).

Fine needle aspiration of the conglomerate excluded a malignancy. Further follow-up of the goitre using ultrasound is necessary. The detection of thyroid conglomerate is considered incidental and does not explain the initial presentation.

\section{Case 3}

A 66-year-old female, known with chronic duodenal ulcer, chronic hepatitis $\mathrm{B}$, was referred for bone evaluation. The family history regarding thyroid or

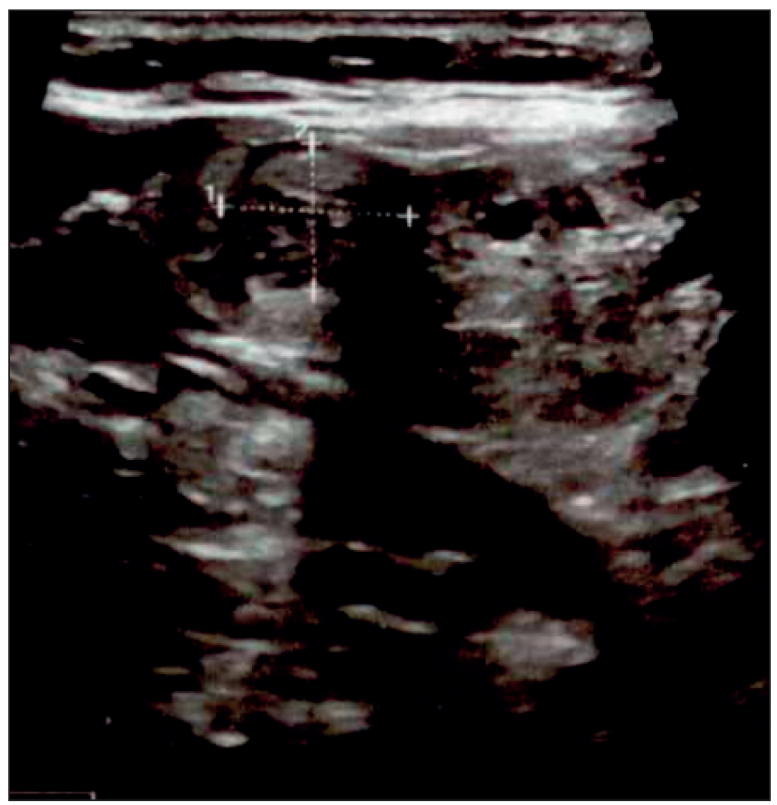

Fig. 4. Hypoechoic nodule on the right lobe in a 66-year-old female with newly discovered multinodular goitre (the diameters are $1.2 \times 0.9 \times 0.9 \mathrm{~cm}$ ). 


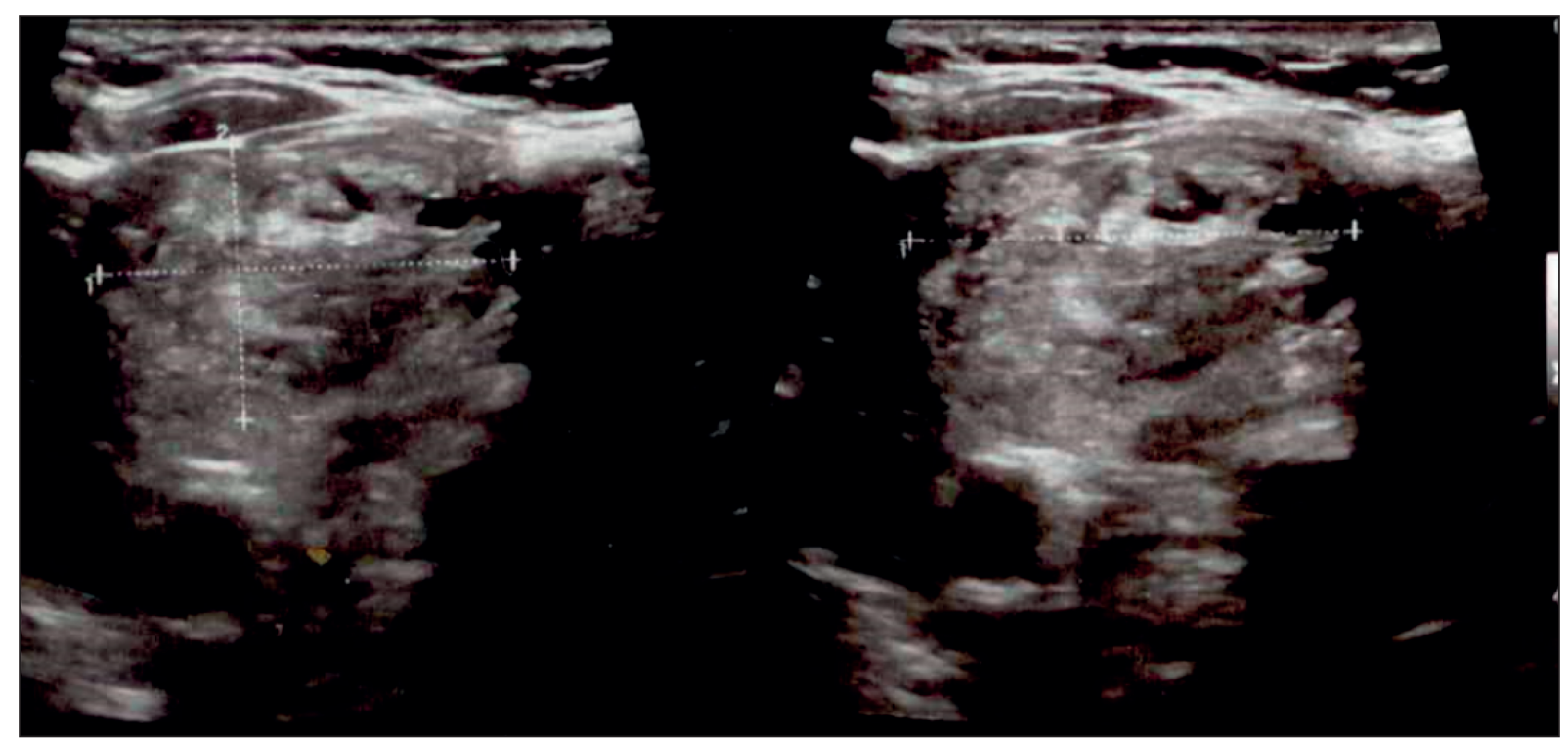

Fig. 5. Ultrasound aspect of a hypoechoic large macronodule in the left thyroid lobe, of $3.1 \times 2.9 \times 1.9 \mathrm{~cm}$.

bone conditions was negative. DXA (Dual-Energy X-Ray Absorptiometry) showed osteoporosis (a lumbar T-score of $-2.7 \mathrm{SD}$, with bone mineral density of $0.854 \mathrm{~g} / \mathrm{sqcm}$ ) and yearly zolendronic acid was recommended. On admission, an enlargement of the thyroid was also detected and confirmed at ultrasound: large right lobe of $2.6 \times 2.5 \times 5 \mathrm{~cm}$, with a hypoechoic nodule of $1.2 \times 0.9 \times 0.9 \mathrm{~cm}$ (Fig. 4).

The left lobe has multiple nodules, the largest being a conglomerate of $3.1 \times 2.9 \times 1.9 \mathrm{~cm}$ (TIRADS4B), and another of $2 \times 1.5 \times 1.4 \mathrm{~cm}$, without latero-cervical lymph nodes involvement (Fig. 5).

TSH was normal and the thyroid antibodies were negative. The patient refused fine needle aspiration and surgery, so follow-up was done, with a stationary ultrasound aspect after 6 months.

\section{Case 4}

A 43-year-old female, without medical history, was referred for an endocrine evaluation after the gynaecological examination detected small bilateral mammary cysts in a patient presenting for mild intermittent mastodynia. She has regular menses, and had no pregnancy. TSH and free-T4 are normal, with lack of thyroid autoimmunity. Prolactin is mildly elevated $(26 \mathrm{ng} / \mathrm{mL}$, the normal value being less than $21 \mathrm{ng} / \mathrm{mL}$ ). Thyroid ultrasound showed a right lobe of $1.8 \times 1.8 \times 4.7 \mathrm{~cm}$, a left lobe of $1.8 \times 1.7 \times 5.4 \mathrm{~cm}$, with a conglomerate on the inferior part, of $3.3 \times 1.8 \times 1.9 \mathrm{~cm}$, with small areas of resolution and a few nonspecific latero-cervical adenopathies. Fine needle aspiration showed Hürthle cells and the patient was referred for surgery, which confirmed the follicular adenoma. Lifelong levothyroxine therapy is necessary.

\section{Case 5}

A 41-year-old female, with subtotal hysterectomy for uterine fibroma 7 years before, presented for intermittent palpitations, induced by supraventricular extrasystoles. TSH was normal, while ultrasound showed a mildly increased right lobe of $2 \times 1.6 \times 4.3$ $\mathrm{cm}$, and a normal left lobe of $1.6 \times 1.3 \times 3.4 \mathrm{~cm}$ (Fig. 6).

The thyroid hypoechoic background is associated with multiple bilateral micronodular masses, displayed as small conglomerates on both lobes: the right lobe had $4-5$ images of maximum $0.43 \mathrm{~cm}$ and the left lobe has an inhomogeneous conglomerate of $0.9 \times 0.9 \times 0.8 \mathrm{~cm}$ (Fig. 7). Except for beta-blockers, no specific therapy is recommended for the moment.

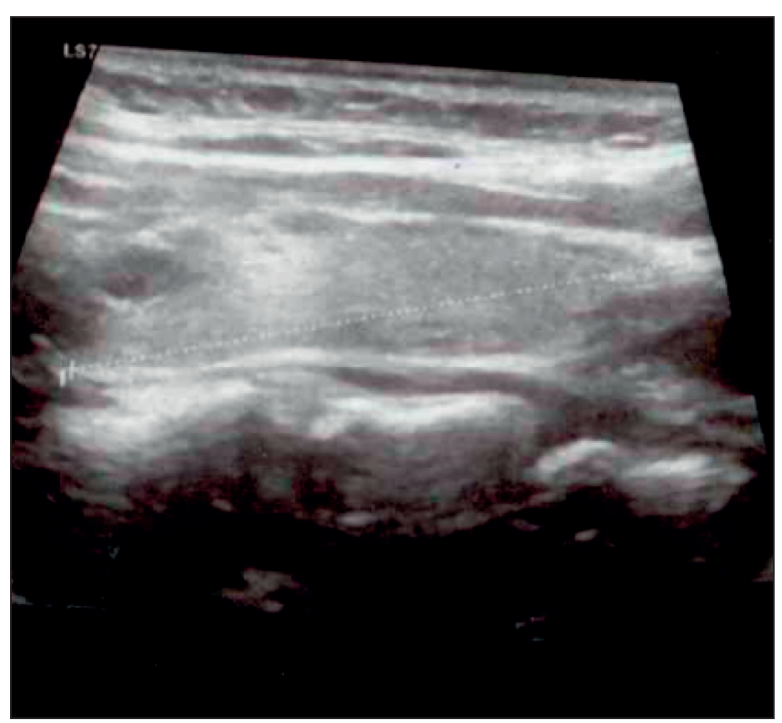

Fig. 6. Ultrasound. Mild enlargement of the right thyroid lobe in a 41-year-old female admitted for arrhythmia. 


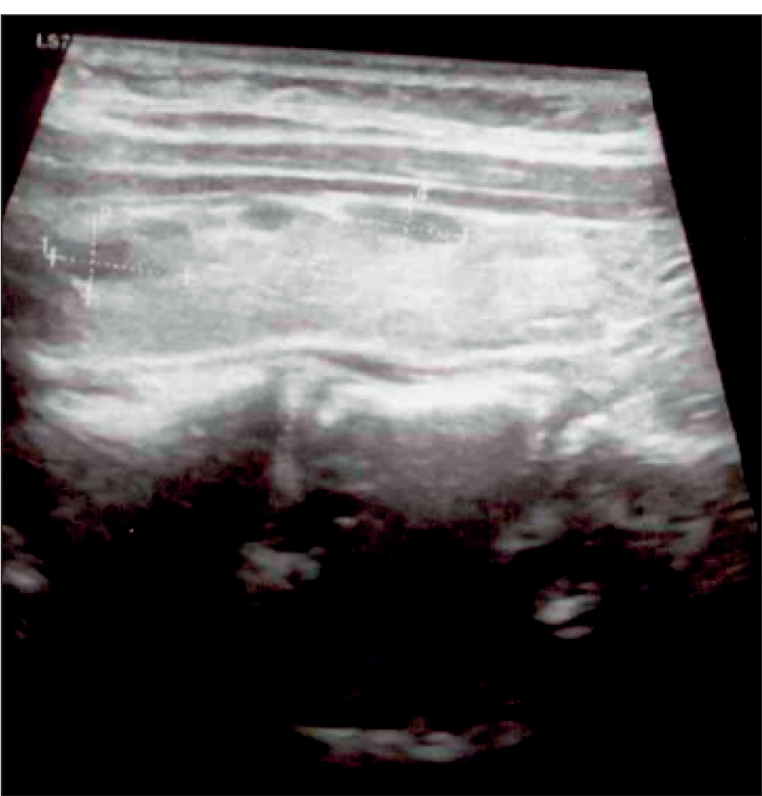

Fig. 7. Thyroid ultrasound of the right lobe: small nodules of less than $1 \mathrm{~cm}$, with hypoechoic aspect and a well shaped form.

Thyroid ultrasound re-evaluation every 6-month was recommended.

\section{Discussion}

Thyroid ultrasound is an exceptional practical diagnostic method in women of reproductive age or of menopausal status ${ }^{4,5}$. The case with Hürthle cells is a particular high-risk situation, because of the mentioned cells, but the malignancy was not confirmed after histopathological report ${ }^{6-8}$. Also, the case no. 4 had a mild increase of prolactin, which is not typically related to thyroid nodules ${ }^{9-11}$. Recent studies showed an increased risk of thyroid enlargement and nodularity in patients with prolactinoma or other neuroendocrine tumours, but not of thyroid cancer $^{9.11}$. High prolactin values may be related to mammary cysts of different dimensions, but not to similar lesions of the thyroid ${ }^{9-11}$.

\section{Conclusions}

The use of thyroid ultrasound represents a very practical method in daily gynaecological endocrinology. The detection of a nodule may be related to routine menopausal evaluation, may be associated with clinical examination for bone menopausal status or may be associated to thyroid function assessment, if hot flushes mimic hyperthyroidism.

\section{Compliance with Ethics Requirements:}

„The authors declare no conflict of interest regarding this article"

"The authors declare that all the procedures and experiments of this study respect the ethical standards in the Helsinki Declaration of 1975, as revised in 2008(5), as well as the national law. Informed consent was obtained from all the patients included in the study"

"No funding for this study"

\section{References}

1. Remonti LR, Kramer CK, Leitão CB, Pinto LC, Gross JL. Thyroid ultrasound features and risk of carcinoma: a systematic review and meta-analysis of observational studies. Thyroid 2015;25(5):538-50.

2. Dighe M, Barr, R, Bojunga J, et al. Thyroid ultrasound: state of the art. Part 1 - Thyroid ultrasound reporting and diffuse thyroid diseases. Med Ultrason 2017;19(1):79-93.

3. Dighe M, Barr R, Bojunga J, et al. Thyroid ultrasound: state of the art. Part 2 - thyroid ultrasound reporting and diffuse thyroid diseases. Med Ultrason 2017;19(2):195-210.

4. Paraschiv B, Dediu G, Iancu A, Bratu O, Diaconu C. Superior vena cava syndrome - review. Arch Balk Med Union 2017;52(1):39-43.

5. Diaconu C, Balaceanu A, Ghinescu M. A neck mass that disapears at compression: is it a reason for concern? Acta Medica Mediterranea 2015;31(2):339-341.

6. Stanciu M, Zaharie IS, Bera LG, Cioca G. Correlations between the presence of Hurthle cells and cytomorphological features of fine-needle aspiration biopsy in thyroid nodules. Acta Endo (Buc) 2016;12(4):485-490.

7. Straccia P, Santeusanio G, Pierconti F, Brunelli C, Fadda G. Cytologic diagnosis of oncocytic neoplasms of the thyroid gland: the Importance of the clinical scenario. Appl Immunohistochem Mol Morphol. 2018 Oct 24. doi: 10.1097/ PAI.0000000000000713. [Epub ahead of print]

8. Eisa N, Khan A, Akhter M, et al. Both ultrasound features and nuclear atypia are associated with malignancy in thyroid nodules with atypia of undetermined significance. Ann Surg Oncol 2018;25(13):3913-3918.

9. Poiana C, Chirita C, Carsote M, Hortopan D, Goldstein A. Galactocele and prolactinoma - a pathogenic association? Maturitas 2009;62(1):98-102.

10. Li H, Li J. Thyroid disorders in women. Minerva Med 2015;106(2):109-14.

11. Tam AA, Kaya C, Aydın C, Ersoy R, Çakır B. Differentiated thyroid cancer in patients with prolactinoma. Turk J Med Sci 2016;46(5):1360-1365.

12. Poiana C, Carsote M, Ardeleanu C, et al. The value of the immunohistochemistry in a case of gastric neuroendocrine tumor and thyroid metastasis. Rom J Morphol Embryol 2011;52(1):187-92. 